
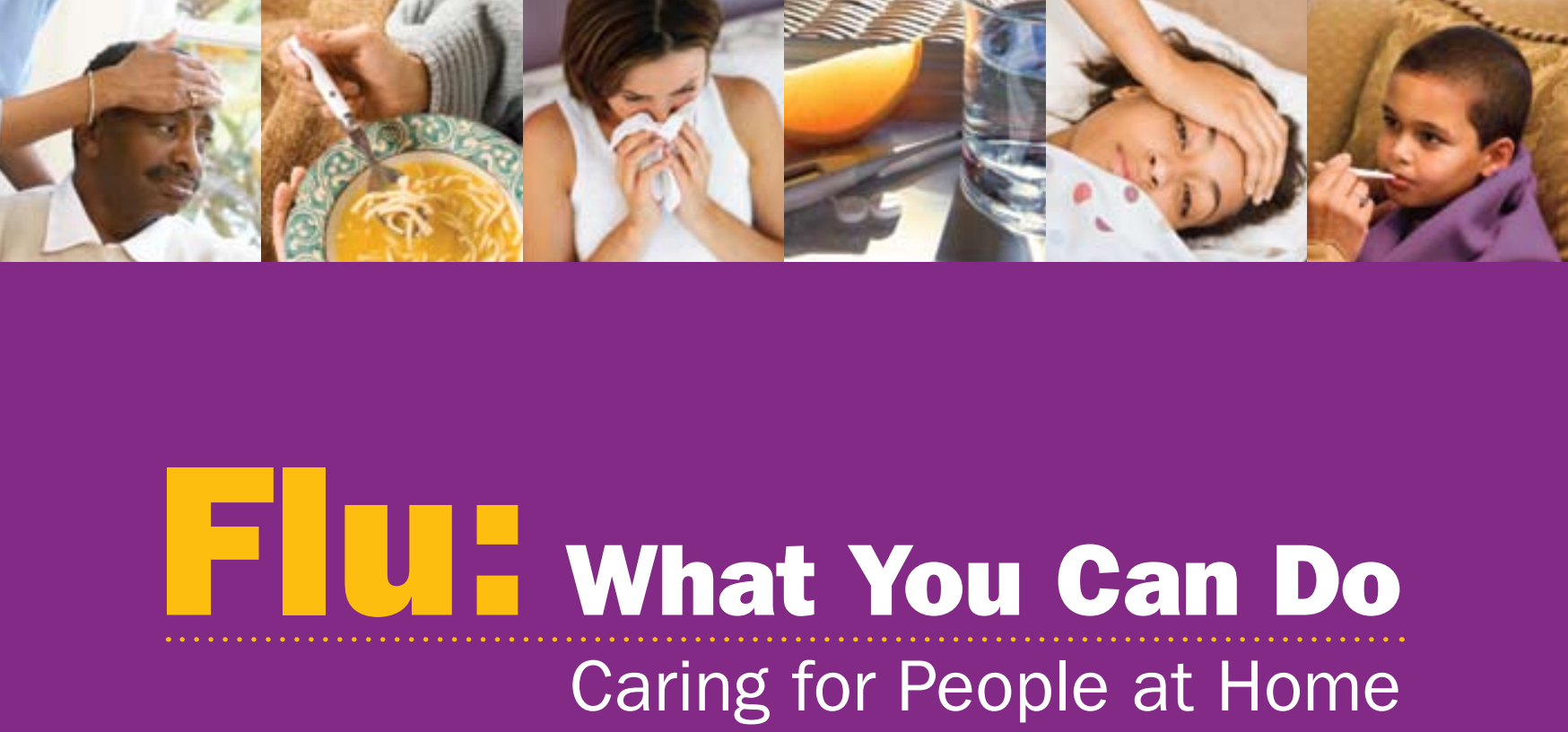


\section{What is the flu?}

Seasonal flu ("the flu")

is caused by a virus that infects your lungs, nose, and throat and makes you sick. Flu season starts in early winter, and continues through early spring every year. The flu comes on very quickly and makes you feel very sick. Most people will feel better within a week
Symptoms include:

- Fever

- Tiredness/weakness

- Severe muscle and

joint aches

- Dry cough

- Headache

- Sore throat

- Runny/stuffy nose

A flu pandemic is caused by a new virus. It is different from the seasonal flu because:

- Many people around the world could get sick at the same time.

- People could get sick at any time of year.

The most important thing to know about a flu pandemic is that the symptoms people have and the way you care for someone who is sick are very similar to the seasonal flu.

\section{What is the common cold?}

The common cold is caused by germs that affect your nose more than any other part of your body.
Symptoms include:

- Stuffy nose

- Sneezing

- Runny nose

- Sore throat

- Wet cough
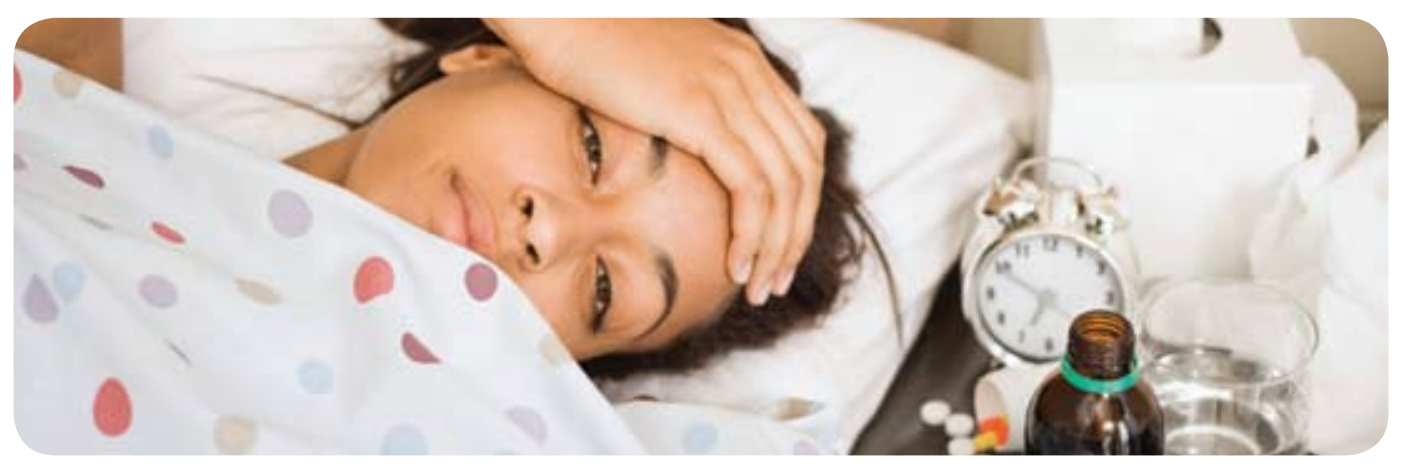


\section{Is it a cold or is it the flu?}

\begin{tabular}{|l|l|}
\hline \multicolumn{2}{|c|}{ KEY DIFFERENCES } \\
\hline WITH A COLD: & WITH THE FLU: \\
\hline You almost never have a fever. & You have a fever. \\
\hline You feel stuffiness in your head. & Your entire body feels sick. \\
\hline You feel a little sick. & You feel very sick. \\
\hline You can have a cold any time of year. & $\begin{array}{l}\text { You can have the flu starting in } \\
\text { early winter and continuing through } \\
\text { early spring. }\end{array}$ \\
\hline There is no shot to protect you. & You can get a shot to protect yourself. \\
\hline
\end{tabular}

How do people get the flu?

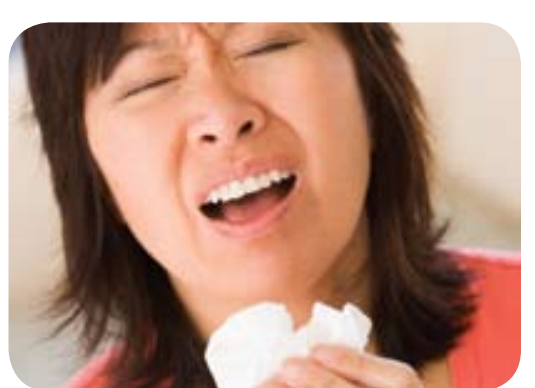

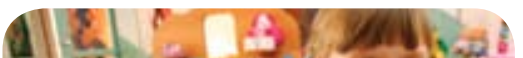

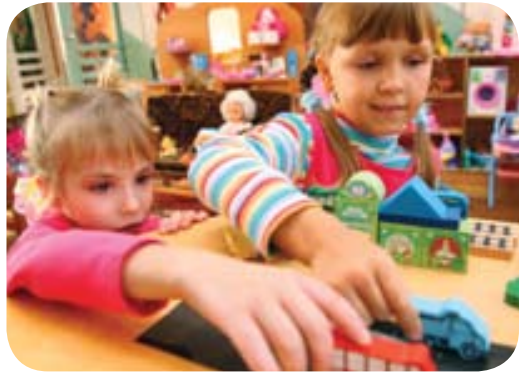

Flu spreads easily from person to person.

When people with the flu cough or sneeze, the

flu virus is in the wet spray that comes out of

their nose and mouth.

- If you are near them, you can breathe in the

virus and get sick.

- The flu virus also gets on things you touch like doorknobs, phones, and toys. After touching

these objects, the virus can infect you when you touch your mouth, nose, or eyes. 
Lower your chances of

\section{getting \& spreading the flu:}

- Get a flu shot every year to prevent the flu!

- Cover your mouth and nose with a tissue when you cough or sneeze. If you don't have a tissue, cough into

your inner elbow.

- Keep your hands away from your

eyes, nose, and mouth.

- Use a household cleaner to clean

things that are touched often like:

" Door and refrigerator handles

„ Computer keyboards/mouse

"Phones

"Kids' toys

- Wash your hands often with soap and warm water, or use an alcoholbased hand gel.

- Keep about 3 to 6 feet between yourself and other people.

- If you are sick, stay home. You can

spread the flu even if you feel better.

"Adults can spread the flu for about 5 days.

" Kids can spread the flu for 7 days.

- If you are breastfeeding your baby and have the flu, you might want to wear a facemask so your baby doesn't get sick.

\section{Get a flu shot every year!}

Anyone who wants to

lower their chances of

getting the flu or giving it

to someone else should

get a flu shot every year.

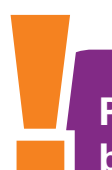

Pneumonia can

be a serious side

effect of the flu. Ask

your doctor if you

also should get a

pneumonia shot.
Some of us are more likely to have problems if we get the flu, so it's very important to get a flu shot every year. This includes:

- Children 6 months through 18 years old

- People 50 years of age or older

- Pregnant women

- People with certain health problems like diabetes, asthma, or heart disease

Talk to your doctor about getting a shot if you have other health problems.

Also, it is extra important to get a flu shot if

you live with or take care of:

- Children younger than 5 years old

- People 50 years of age or older

- Pregnant women

- People with certain health problems 


\section{How to take care of}

\section{someone with the flu:}

When someone has the flu they feel very sick and tired. They feel achy, have a fever, and may get dehydrated. Here are signs and symptoms you can look for, and ways you can help someone feel better.
Fever is a common symptom of the flu. It can

come on suddenly and last for 3 to 5 days.

- A fever is a higher body temperature than

normal. It is measured using a thermometer.

- Temperatures can be measured by: »Rectum (bottom)

" Ear

"Mouth

"Armpit

- Talk to your doctor about the different types of thermometers you can use, and which one will work best for you and your family members. " Digital thermometers are much safer than glass. Glass thermometers can break easily, and the mercury in them is very dangerous.
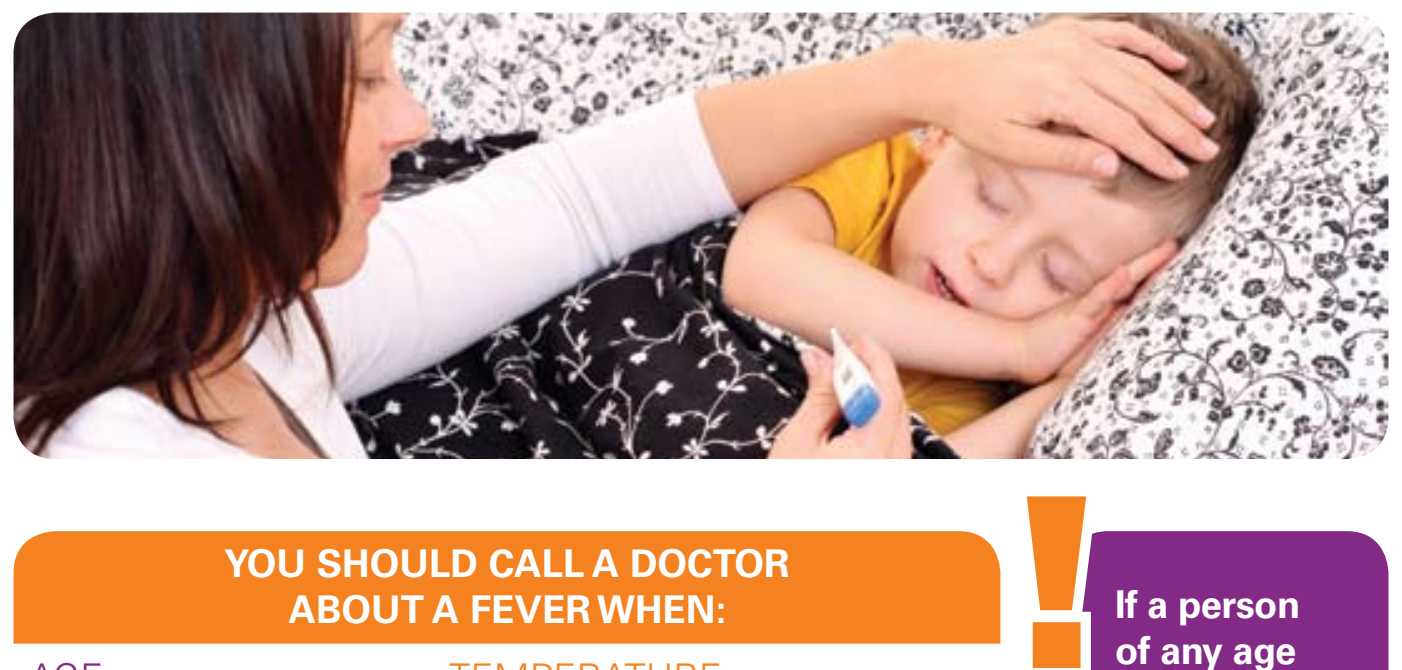
AGE: $\quad$ TEMPERATURE: $\quad$ of any age Under 3 months old Fever of $100.4^{\circ} \mathrm{F}\left(38^{\circ} \mathrm{C}\right)$ or higher 3 months to 5 years old Fever of $102^{\circ} \mathrm{F}\left(38.9^{\circ} \mathrm{C}\right)$ or higher Over 5 years old $\quad$ Fever of $104^{\circ} \mathrm{F}\left(40^{\circ} \mathrm{C}\right)$ or higher

for more

than 3 days,

you should

call a doctor. 
You can buy these at most stores and pharmacies.

Use medicine that is right for the person's age.

Follow label instructions very carefully.

Never give aspirin
to children 18 and
younger unless it
is recommended
by a doctor. It can
cause a dangerous
illness called Reye's
Syndrome.

There are a few ways to treat a fever and make someone feel more comfortable:

- Give fever-reducing medicines like:

" Acetaminophen (Tylenol $\circledast$ or store brand) ") lbuprofen (Advil $\circledast$, Motrin $®$, or store brand)

"Aspirin (Bayer ${ }^{\circledR}$ or store brand)

- Keep the room comfortably cool.

- Make sure they are wearing light-weight

clothing.

- Have them drink fluids, especially water

- Consider sponging them with lukewarm

water if they have a high fever.

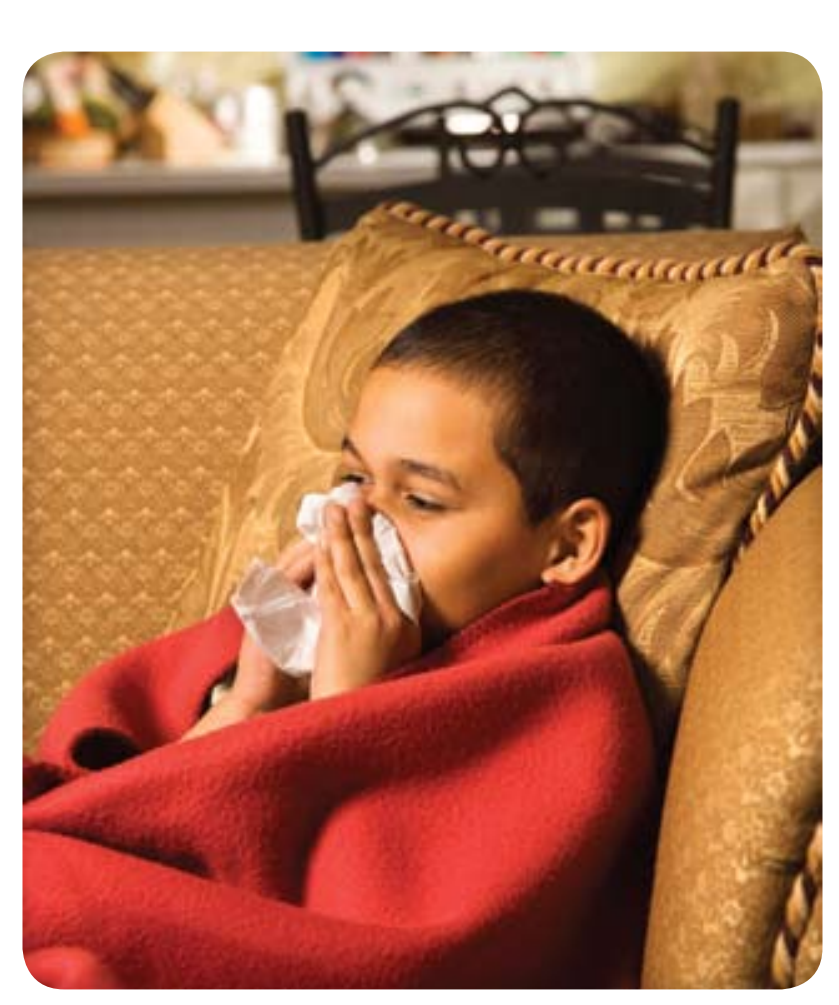

Doctors say we should not use

alcohol rubs or

cold water baths to

bring a fever down.

Alcohol can be

absorbed through

the skin and make

a child sick. Cold

water can cause

shivering and make

the bad effects of

the fever worse. 


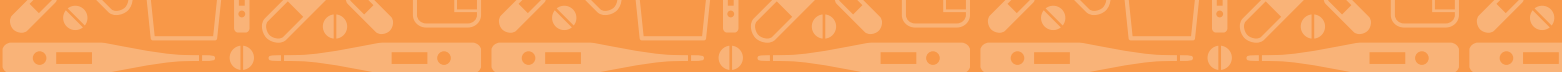

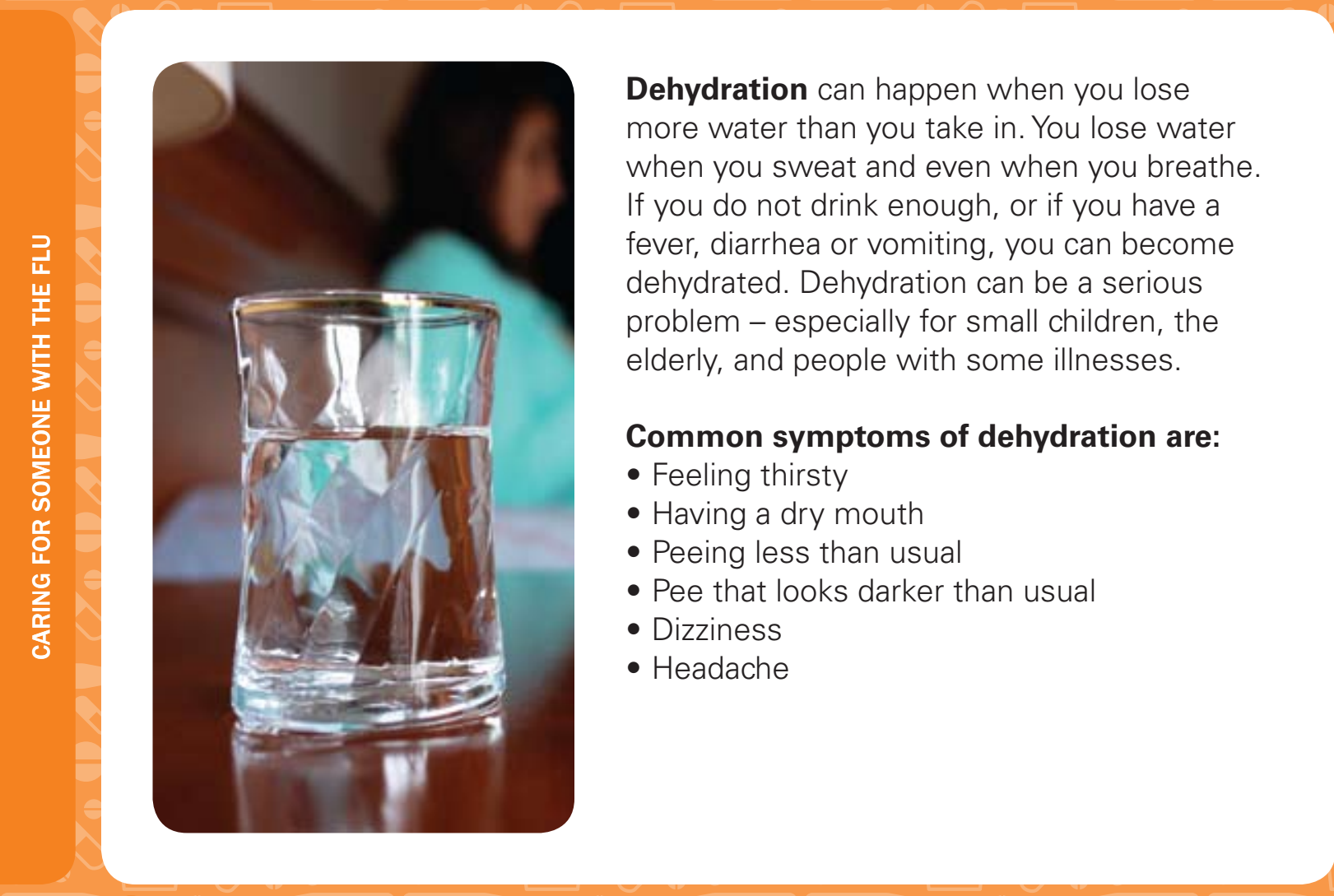

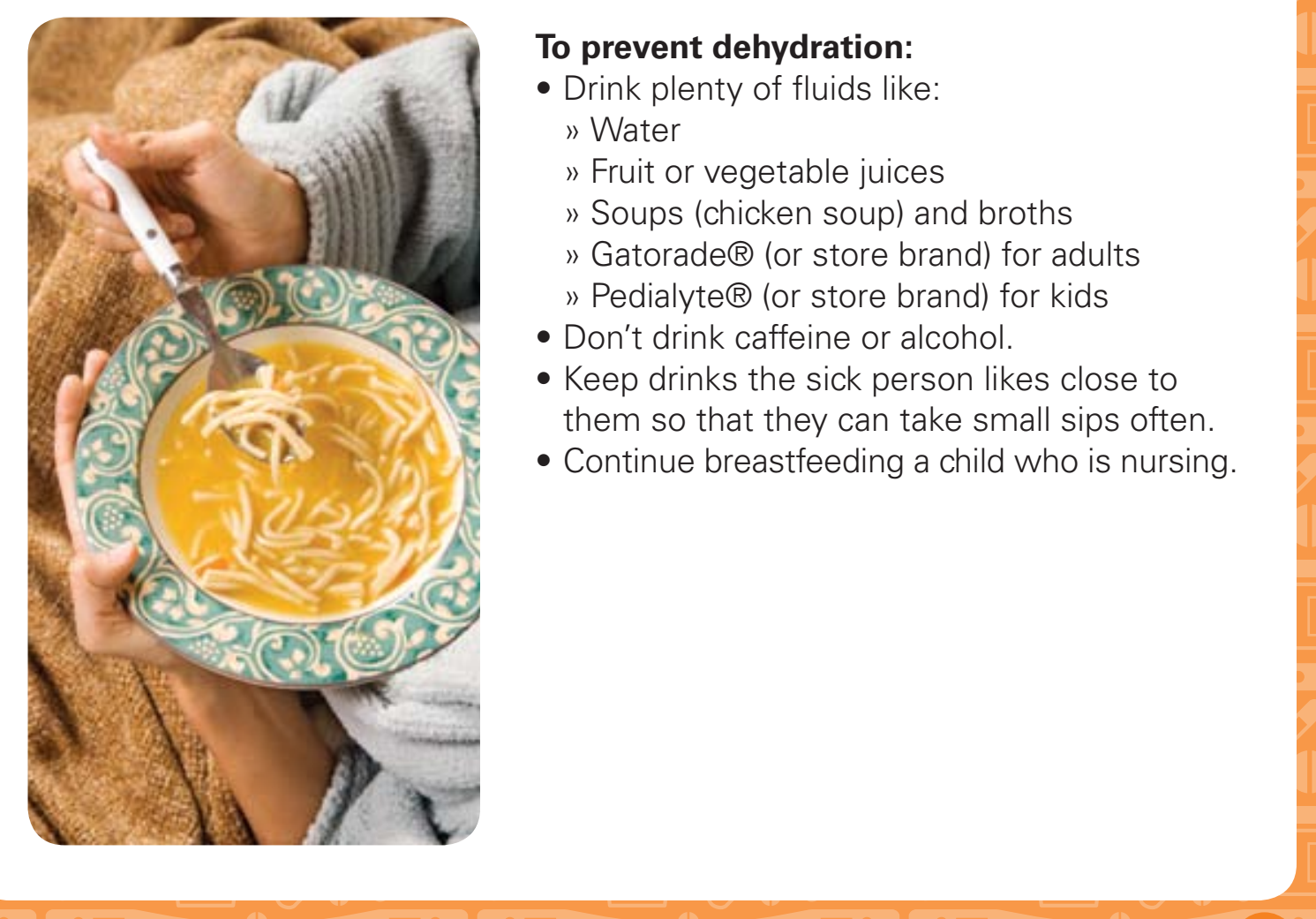


If you are pregnant, or if you have a

health problem like diabetes, asthma,

or heart disease,

it is important to

call your doctor

when the first flu

symptoms appear.

Your health condition could be made worse by the flu.
Call a doctor if someone:

- Has a fever that lasts more than 3 days

- Has a fever or cough that goes away for 24

hours or more and then returns

- Has a fever with:

" a stiff neck

" a very bad headache

" a severe sore throat

" an earache

" a rash

- Has less pee or dark pee

- Has green, brown-colored, or bloody mucus

that comes up when they cough

- Has severe vomiting or vomits for a long time

- Has difficulty drinking or taking a bottle

- Is very fussy or sleepy (infants and children)

- Has any other unusual symptoms or concerns

- Has not gotten better after a week

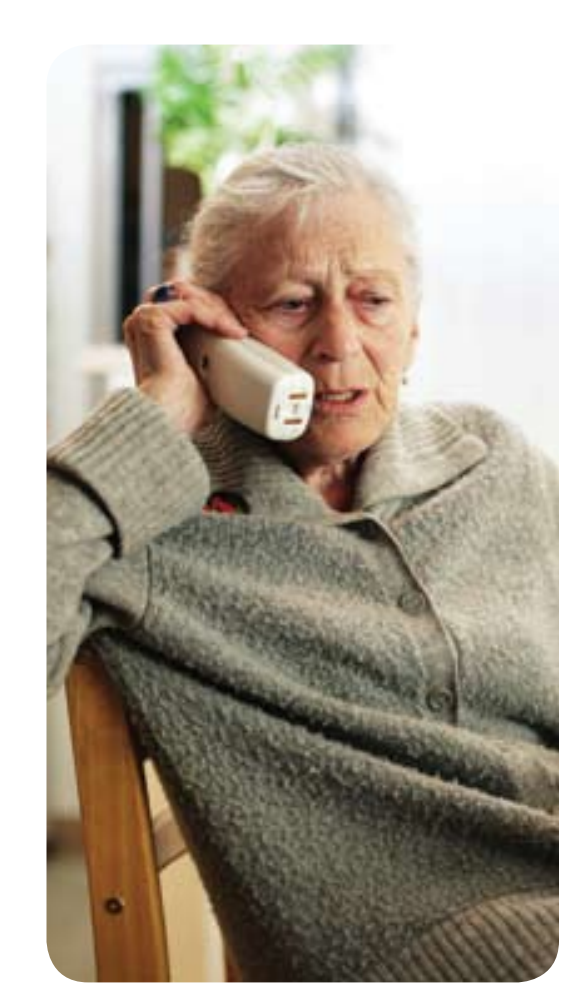

Call 911 for an emergency if someone:

- Is having trouble breathing - breathing is

very fast, difficult, or painful

- Is having chest pain

- Is confused or unaware of their surroundings

- Is unable to wake up

- Has changes in their speech, or speaks in a

way you can't understand

- Can't walk or sit up

- Has skin that is bluish or gray in color

- Has a seizure (uncontrolled twitching or shaking) 


\section{How to prepare before}

\section{you get sick:}

Build a Flu Care Kit filled with the supplies you'll need if you get sick.
Keep the following supplies at home to use in case someone gets the flu. Get these

supplies before you or someone you care for

gets sick. It can be hard to find the time or energy to go to the store to buy what you need

when someone is sick.

- A digital thermometer

- Non-aspirin medicines like:

"Acetaminophen (Tylenol ${ }^{\circledR}$ or store brand)

" Ibuprofen (Advil $\AA$, Motrin $®$, or store

brands, etc.)

- Drinks - like water, fruit juice, soups, and

sports drinks

- Soap and alcohol-based hand gel

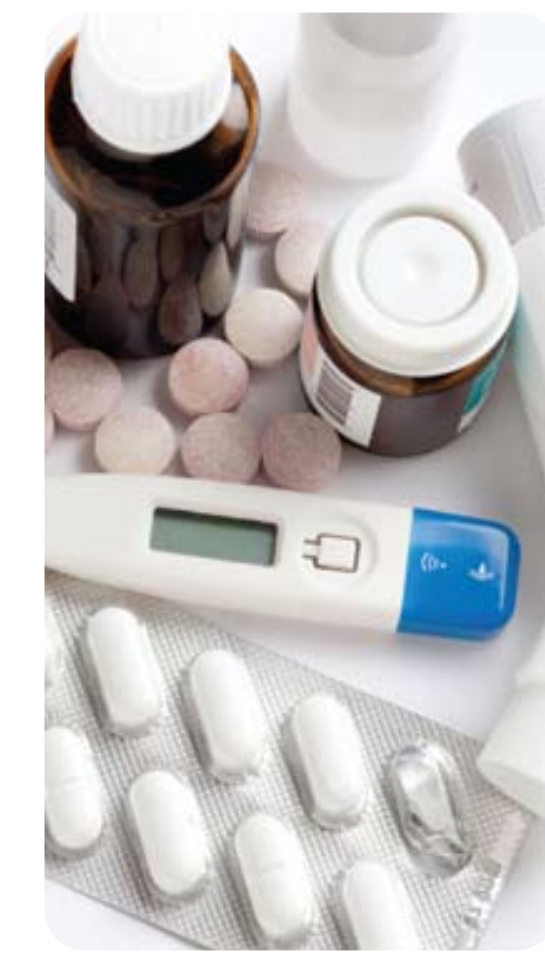

- Food that is easy to digest (crackers,

oatmeal, rice, etc.)

- Extra supply of food, medicine, or equipment

for those with special needs

- Cleaning supplies - household disinfectant,

paper towels, trash bags

- The name and phone number of the family doctor

Check the expiration dates on all your supplies every 6 months. 


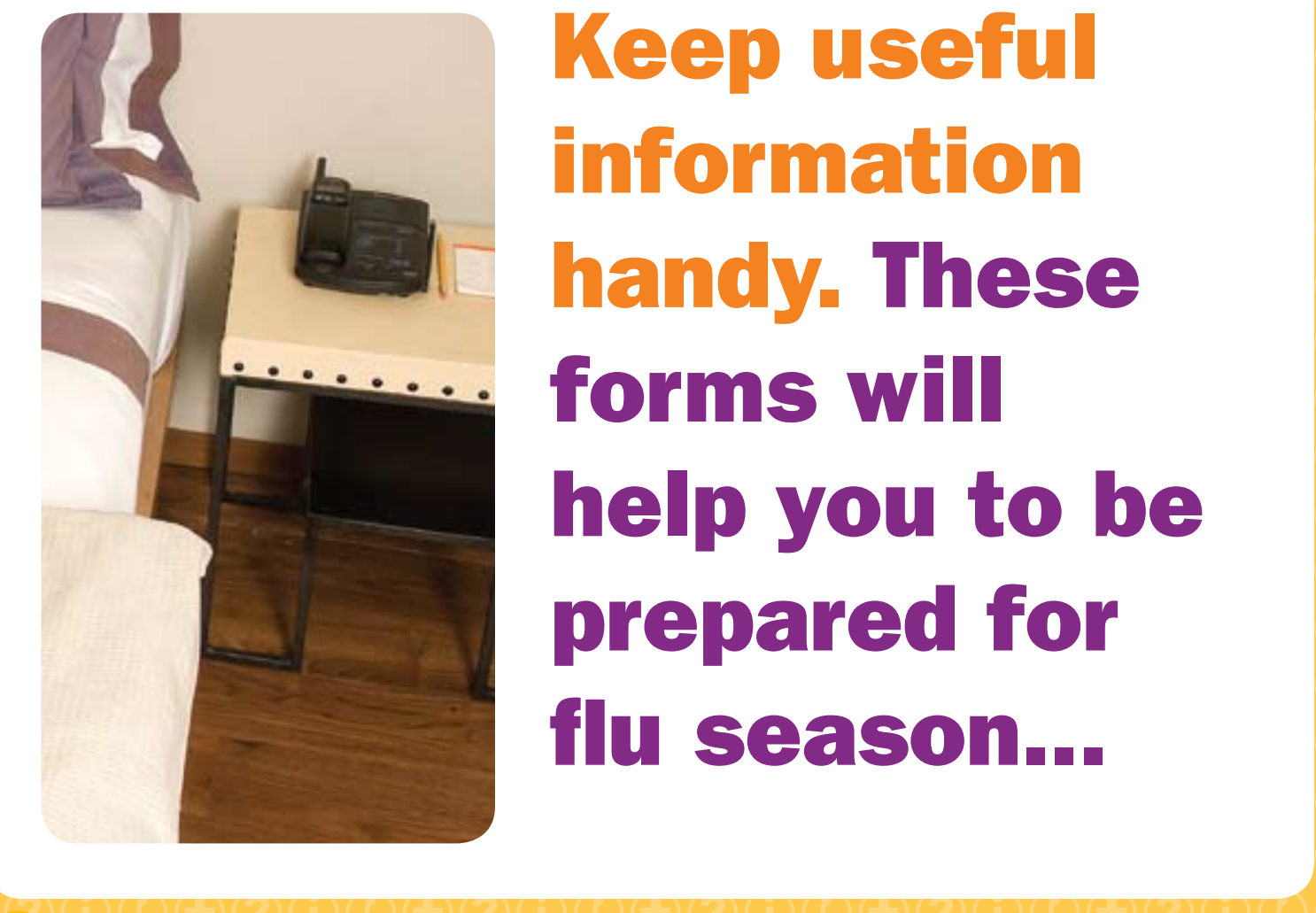

\section{My flu care information:}

Doctor's name and phone number:

Pharmacy phone number:

Phone number of family or friends available to help when needed:

MEDICINES THAT YOU OR FAMILY MEMBERS TAKE REGULARLY

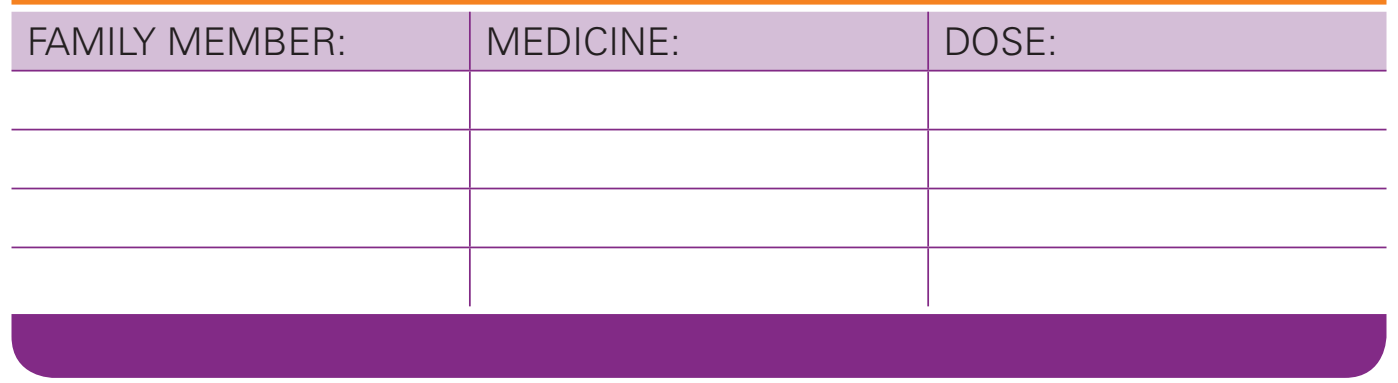


ALLERGIES THAT YOU OR FAMILY MEMBERS HAVE

\begin{tabular}{l|l}
\hline FAMILY MEMBER: & ALLERGY:
\end{tabular}

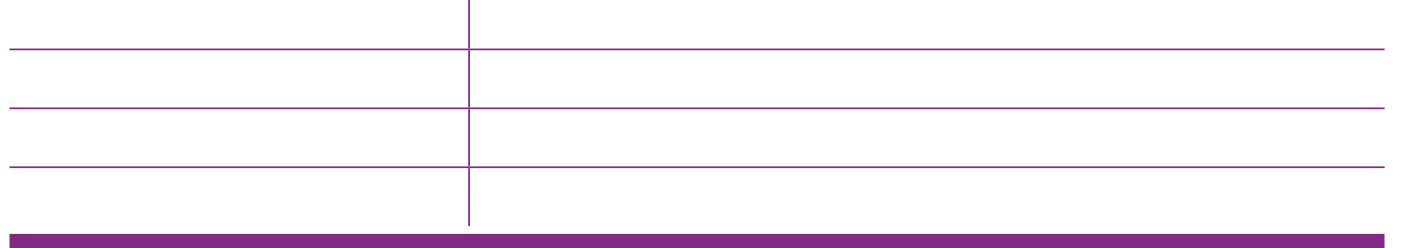

SPECIAL DIETS THAT YOU OR FAMILY MEMBERS FOLLOW \begin{tabular}{l|l} 
FAMILY MEMBER: & SPECIAL DIETS:
\end{tabular}
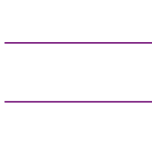

\section{Summary for your doctor:}

Reason you are calling:

Symptoms of patient:

How long has the patient been sick?

Age of patient:

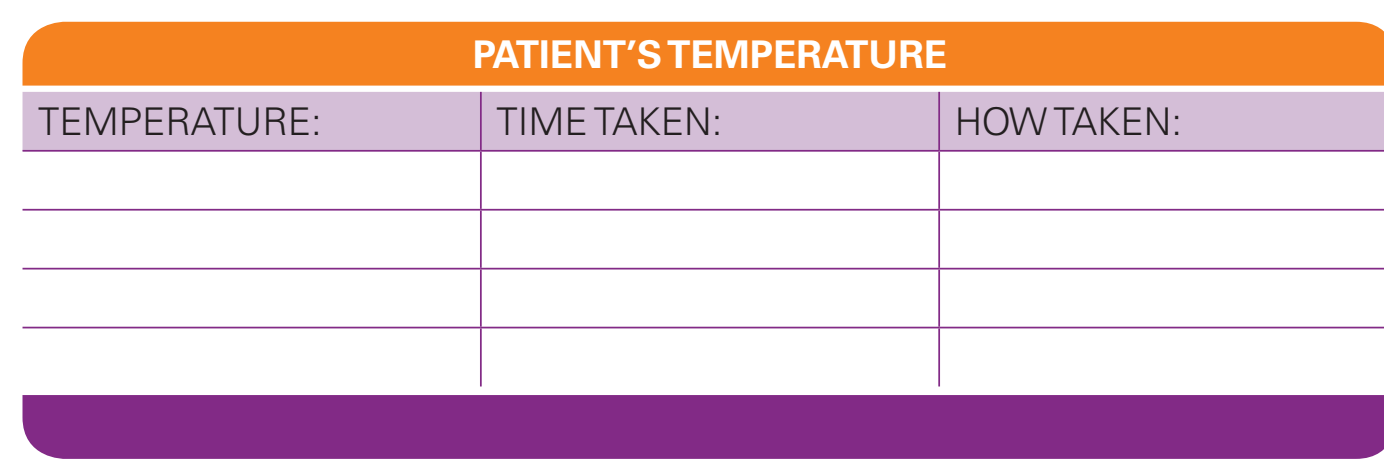


For more information, please visit:

(1)(3)(3)(3) (3)

(3)(3)(1)(3)(1) (1)

www.mass.gov/dph/flu 2)(1)(3)(1)(3) (1)(2)(1)(1) (3)(1)(3)(1)(1) (1)(2)(1)(2)(1)

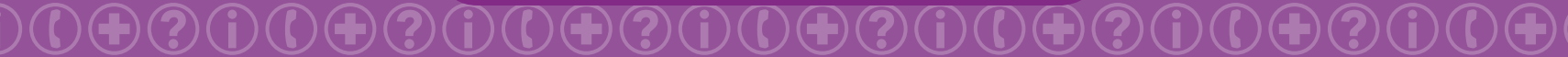

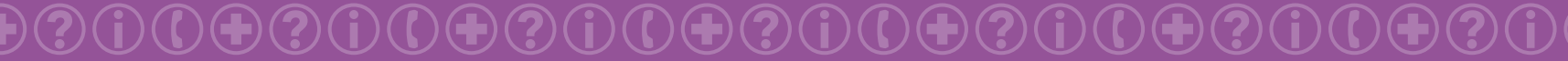

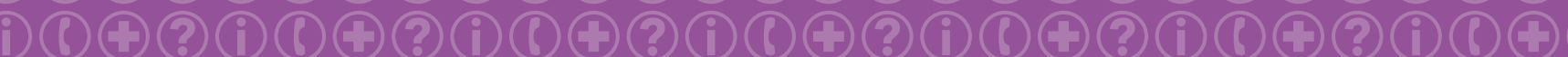

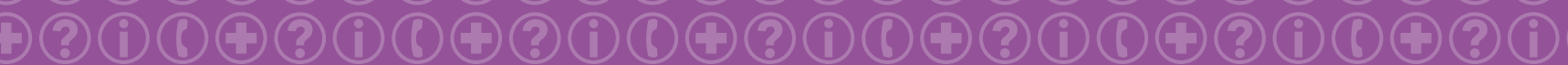

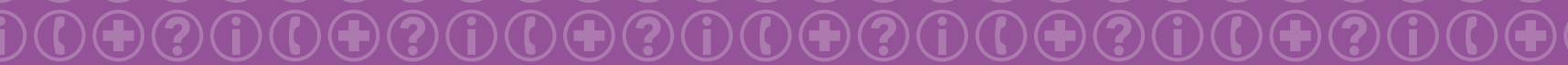
(3) (1) (1) (3) (1) (3) (1) (1) (3) (1) (1) (1) (1) (3) (1) (1) (1)

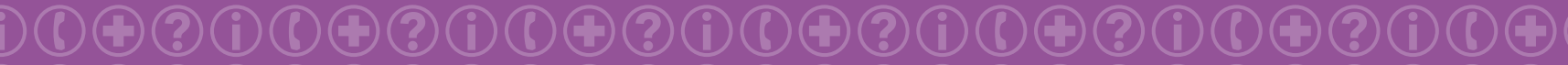

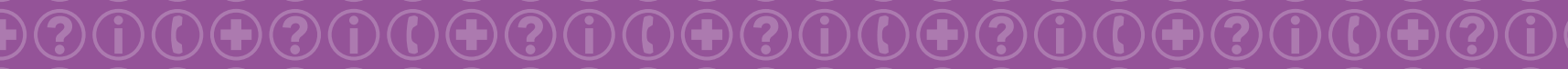




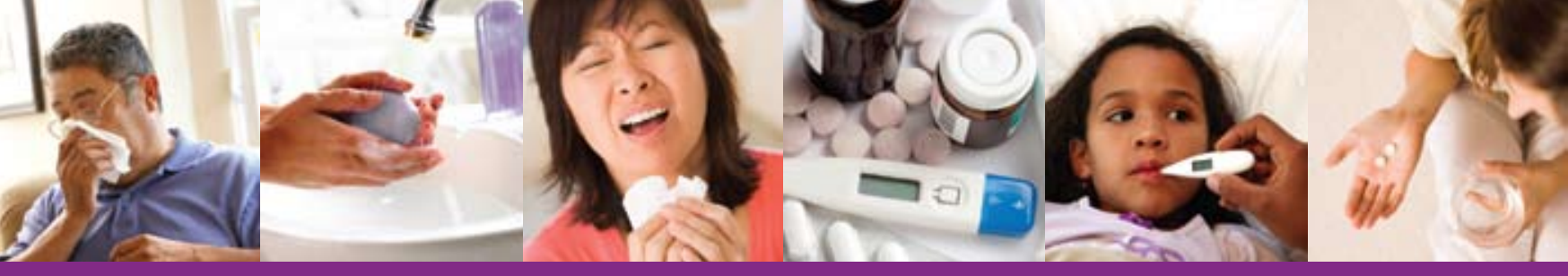

Massachusetts Department of Public Health

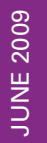

